\title{
Fungal Infections: Their Diagnosis and Treatment in Transplant Recipients
}

\author{
David H. Van Thiel, Magdalena George, and Christopher M. Moore
}

Section of Hepatology, Rush University Medical Center, Chicago, IL 60612, USA

Correspondence should be addressed to David H. Van Thiel, david_vanthiel@rush.edu

Received 7 February 2012; Accepted 23 April 2012

Academic Editor: Giuliano Ramadori

Copyright (๑) 2012 David H. Van Thiel et al. This is an open access article distributed under the Creative Commons Attribution License, which permits unrestricted use, distribution, and reproduction in any medium, provided the original work is properly cited.

Systemic fungal infections typically occur in individuals who are seriously ill with recognized risk factors such as those frequently found in transplant recipients. Unfortunately, they are often diagnosed late, when the efficacy of the available treatments is low, often less than $50 \%$, and the cost in terms of lives lost, hospital length of stay, and total hospital costs is substantially increased. The application of antifungal therapies associated with reported efficacy rates greater than $50 \%$ are those used prophylactically. When used prophylactically, these infections are reduced in greater than $95 \%$ of the expected cases. The choice of a prophylactic agent should be based upon its ease of administration, lack of adverse effects, reduced likelihood of potential drug interactions, and its efficacy in patients with established risk factors and comorbid disease processes that include renal, hepatic, and chronic pulmonary disease. The indications for the use of currently available antifungal agents, their adverse effects, drug interactions, ease of dosing, and applicability in patients with preexisting disease states, and especially in liver transplant recipients, are presented in this paper.

\section{Epidemiology}

The frequency and variety of invasive fungal infections have increased greatly over the last three decades as a consequence of changes in medical and surgical care, particularly in intensive care units which utilize invasive catheters for monitoring, coupled with the use of more potent immunosuppression and antibiotic agents [1]. The current increase in invasive fungal infections is the result of changes in disease management with the use of powerful immunosuppressive agents, multiple antibiotics, the use of organ support procedures that include mechanical ventilation, hemodialysis and venovenous hemofiltration, and parental hyperalimentation. These medical and procedural advances coupled with the application of more aggressive antineoplastic therapies and transplantation of individuals with preexisting cardiopulmonary, renal, and hepatic disease processes have changed the frequency and approach to fungal infections. Specifically, as a direct result of these advances and therapeutic successes, the population at risk for fungal infections has expanded greatly $[2,3]$. In the early 1980 s, systemic candidiasis was recognized as an important medical problem. The mortality associated with candidiasis increased steadily until 1988, when it peaked at a rate of 0.6 per 100,000 per population [4]. As a result of recent advances in the treatment of invasive candidiasis, mortality stemming from Candidemia has decreased annually since its peak. Nonetheless, systemic candidiasis remains the fourth most common nosocomial bloodstream infection [3]. Although the number of bloodstream infections due to C. albicans has decreased, those due to other Candida species, particularly $C$. glabrata, C. krusei, and C. parapsilosis, have increased [1].

In contrast to candidiasis, infections and death as a result of other fungal pathogens, particularly Aspergillus species, have continued to increase since the late 1980s [4-9]. The mortality of invasive aspergillosis infections remains very high, particularly in transplant recipients despite the use of new diagnostic methods and advances in therapy [10].

The risk for systemic fungal infection is greatest in those with hematologic diseases requiring allogeneic hematopoietic stem cell transplantation followed by autologous grafts, other hematologic disorders associated with severe and prolonged leukopenia, those with solid organ neoplasms, and solid organ transplanted individuals [11-20]. The presence 
of confounding chronic pulmonary disease and heart/lung transplantation increases the risk for infections due to yeasts and molds, particularly Aspergillus.

The specific fungal and yeast pathogens experienced in hematopoietic stem cell transplantation and solid organ transplantation differ dramatically. Specifically, invasive Aspergillus and other molds account for $70 \%$ of the fun$\mathrm{gal} / \mathrm{mold}$ infections in hematopoietic stem cell recipients, while only a minority of solid organ transplant recipients acquire these infections unless they have confounding chronic pulmonary disease or the recipient is exposed to a hospital construction site or dust containing molds [10$13,17,18]$. Nonmold infections in hematopoietic stem cell recipients account for $30 \%$ of the total fungal $/ \mathrm{mold}$ infections in this population. In contrast, almost all of the infections in solid organ transplant recipients are due to fungal agents with only a minority occurring as a result of Aspergillus and other molds. In this later group, invasive candidiasis accounts for $50 \%$ of the total infections followed in order by Cryptococcus (7\%), endemic mycosis (6\%), and finally all other fungal or mold infections combined account for $37 \%$ of the total. These differences in the pattern of invasive fungal infections between hematopoietic stem cell transplant and solid organ transplant are, at least in part, due to the routine use of azole agents for prophylaxis in the former group, but not those in the latter.

\section{Differences due to the Type of Organ Transplant}

As expected, the overall incidence of systemic fungal infections is greatest in those receiving bone marrow transplants as compared to solid organ transplants. The incidence varies within each group as a function of the type of marrow transplanted and solid organ transplanted. In marrow recipients, the incidence is greatest in those receiving mismatched related and unrelated allogeneic stem cells (5.9\%). Those receiving matched related allogeneic stem cells have a lower incidence of $3.7 \%$ and those receiving autologous stem cells have the lowest incidence $(0.6 \%)$. These rates of infection reflect the major differences in chemoablative therapies used to condition the marrow, the duration of posttransplant cytopenia experienced, and the immunosuppression differences utilized between these various groups [17].

Differences in the incidence and type of systemic fungal infections occurring as a consequence of the particular organ transplanted are seen in solid organ transplant recipients as well. Those receiving lung grafts have the highest incidence $(7.9 \%)$ followed by heart $(3.4 \%)$, then liver $(3.1 \%)$, renal $(1.1 \%)$, and pancreas $(0.7 \%)$. Those receiving lung and heart transplants have a greater incidence of Aspergillus infections while those receiving nonthoracic solid organs experience candidiasis as their major fungal pathogen [14, 17-19]. The risk for candidiasis in solid organ recipients is greatest early after transplantation (first 2-3 months after transplant) and then declines as other fungal pathogens including aspergillosis, histoplasmosis, coccidioidomycosis, and blastomycosis become more prominent, with variation depending on the geographic location of the recipient [2]. The early infections due to candidiasis are a result of the use of indwelling catheters, central lines, abdominal wounds, drains, and secondary operations as well as the use of parenteral nutrition and mechanical ventilation [5]. Late infections that occur months to years after transplantation are a consequence of the life-long immunosuppressive agents that these patients take to prevent rejection and the unique local environmental exposures the recipient experiences.

\section{Cost of Fungal Infections}

The direct costs of fungal infections are substantial [19]. The global cost of candidiasis is 2.5 times that for Aspergillus infections. However, when the global cost is corrected for the number of individuals infected, the individual cost is 2-3-times greater for those with an Aspergillus infection as compared to that experienced by one with candidiasis [19].

\section{Diagnosis of Fungal Infections}

Early diagnosis and treatment are critically important in terms of obtaining a better outcome defined as a reduced morbidity and mortality. The diagnosis of invasive fungal infections is difficult because of the lack of specific signs and symptoms until late in the disease process and the difficulty associated with documenting a diagnosis with current diagnostic tools, obtaining infected tissue required to establish a specific diagnosis, and in some cases defining the isolated agent's sensitivity to the therapeutic regimen being utilized [20].

\section{Therapeutic Definitions}

The high mortality of invasive surgical infections is due in large measure to the delay in recognizing an infection in individuals at risk for severe infections and the difficulty in establishing an early diagnosis as a result of the nonspecific clinical features, low sensitivity of microscopic diagnostic methods, the difficulty in obtaining infected tissue for histologic and microbiologic diagnostic procedures, and appropriately interpreting imaging procedures [20].

As a direct consequence of these factors prophylactic, empiric, and preventative therapies have been developed and utilized. The specific antifungal agent chosen for each of these therapeutic approaches varies between centers and specific types of transplantation. Factors that affect the choice of antifungal agent include characteristics of the patient, the clinical circumstances, and the presence or absence of overt sepsis and/or hemodynamic instability.

Empiric therapy is defined as the initiation of antifungal treatment in an individual at high risk for an invasive fungal infection and manifesting symptoms and/or signs of an infection but without microbiological documentation of the infection. Empiric therapy utilizes a broad-spectrum antifungal agent for 3 or more days until deescalation is possible based upon the specific infection identified, its location, and the patient's clinical status. 
Prophylactic therapy is defined as the use of an antifungal agent with intent to prevent the likelihood of an invasive fungal infection in an individual at high risk for such an infection. Preemptive therapy is defined as the initiation of antifungal therapy based upon the results of an early diagnostic test.

\section{Diagnostic Tools}

Currently available diagnostic tools for establishing a diagnosis of an invasive fungal infection include the following: galactomannan, (1,3)- $\beta$-glucan, and $C$. albicans germ tube antibody detection. Each of these procedures has its own set of problems that limit their widespread application.

The galactomannan assay is an enzymatic immunoassay which has been FDA approved and is used in the United States and Europe. The assay can detect galactomannan in blood 5-8 days on mean (range 1-27 days) before the onset of clinical signs and symptoms of an invasive fungal infection. It is a nonspecific test and only suggests the presence of a fungal infection as it measures a component of fungal hyphae. When positive, the level determined varies as a function of the infectious agent burdens and can be used to monitor the response to therapy [21-24]. Unfortunately, false-positive results occur in $5.7 \%-14.0 \%$ of adults and as high as $83 \%$ in neonates. The cause of these positive results is not entirely clear but the use of piperacillin-tazobactam in adults and cross-reactivity with antigens expressed in Bifidobacterium species in neonates have been suggested as possible causes $[25,26]$.

Overall, the galactomannan assay has moderate accuracy for the diagnosis of an invasive fungal infection in an immunocompromised individual and is more efficacious in those with hematologic malignancies or hematologic stem cell transplant procedures than in those undergoing solid organ transplant procedures [21-24]. Nonetheless, the presence of a positive galactomannan assay result utilizing bronchoaveolar lavage fluid in a solid organ transplant recipient with clinical signs of either a bronchial infection or pneumonia is highly diagnostic in this population $[26,27]$.

The $(1,3)-\beta$-d-glucan assay has been approved by the FDA also and when positive in blood suggests the presence of a fungal infection. It, like the galactomannan assay, is a broad-spectrum fungal marker that requires subsequent microbiological and imaging studies to define the specific infection. Its usefulness reflects the fact that glucans are a critical compound of the cell wall of most pathologic fungi except for Cryptococcus and zygomycetes [28-33].

A major problem with the $(1,3)$ - $\beta$-d-glucan assay is its requirement for endotoxin and glucan-free glassware, and the presence of false positive result as a result of the presence of albumin, immunoglobulins, glucan-containing materials, gram-positive bacteria, and hemodialysis. As a result, its major usefulness is to exclude the possibility of a fungal infection [29-33].

Antibodies to C. albicans germ tube antigens have been useful at detecting invasive candidiasis due to a broad spectrum of Candida species $[34,35]$. It has been most useful in the detection of Candida infections in drug users, hematologic cancer, and transplant recipients, as well as medical patients in an ICU setting $[34,35]$. Its use in solid organ transplant recipients has not been evaluated.

The uses of polymerase chain reactions (PCR) to detect fungal DNAs are available in research laboratories but are not standardized or FDA approved. More bothersome is the fact that because of their sensitivity, they may be positive in samples obtained from patients with colonization rather than infection. Consequently, the diagnosis of an infection rather than colonization may in fact require the use of a less sensitive test for confirmation.

Microbiological cultures of biologic fluids and tissue for the detection of an invasive fungal infection require multiple days and occasionally weeks for the identification of a specific fungal pathogen. This said, they are highly specific and can be used for antifungal resistance testing if necessary.

\section{Available Antifungal Agents (Tables 1 and 2)}

In general, antifungal agents target components of the fungal cell wall that result in defective cell wall homeostasis and induce an osmotic stress that leads to lysis and fungal death. The polyenes (amphotericin) bind to ergosterol, the principle sterol component of the fungal cell membrane resulting in a loss of cell wall integrity. The azoles (fluconazole, itraconazole, voriconazole, and posaconazole) inhibit enzymes involved in ergosterol synthesis. The echinocandins inhibit glucan synthesis. Glucan is a long chain polymer responsible for fungal cell wall stability. It accounts for 30-60\% of the cell wall mass in Candida, Aspergillus, and Saccharomyces species. Importantly, human cells do not contain glucan, thus accounting for the low rate of human toxicity associated with this class of agents.

7.1. Polyenes. Amphotericin has been the principal agent for the treatment of invasive fungal infections for more than half a century. Its efficacy is based upon its ability to bind to ergosterol, the principal sterol in the fungal cell wall, inducing a loss of cell wall osmotic regulation and lysis of the infecting fungus (fungicidal). The limiting factor for its use is nephrotoxicity, particularly a progressive renal dysfunction associated with hypokalemia, renal tubular acidosis, and hypocalcemia. Lipid-based amphotericin preparations have attenuated the nephrotoxicity compared to the original agent but continue to have a similar pattern of adverse effects. Unfortunately, these lipid-based amphotericin preparations do not appear to have greater efficacy and are considerably more expensive than the original material.

The use of predosing hydration regimens with normal saline and a continuous infusion of amphotericin has reduced the fever, chills, and flushing associated with its use, but can be problematic in transplant patients with preexisting renal and/or hepatic dysfunction, who often are volume overloaded complicated further by a low serum albumin level [36]. These same individuals can occasionally experience an acute pulmonary reaction similar to pulmonary edema while receiving amphotericin. 


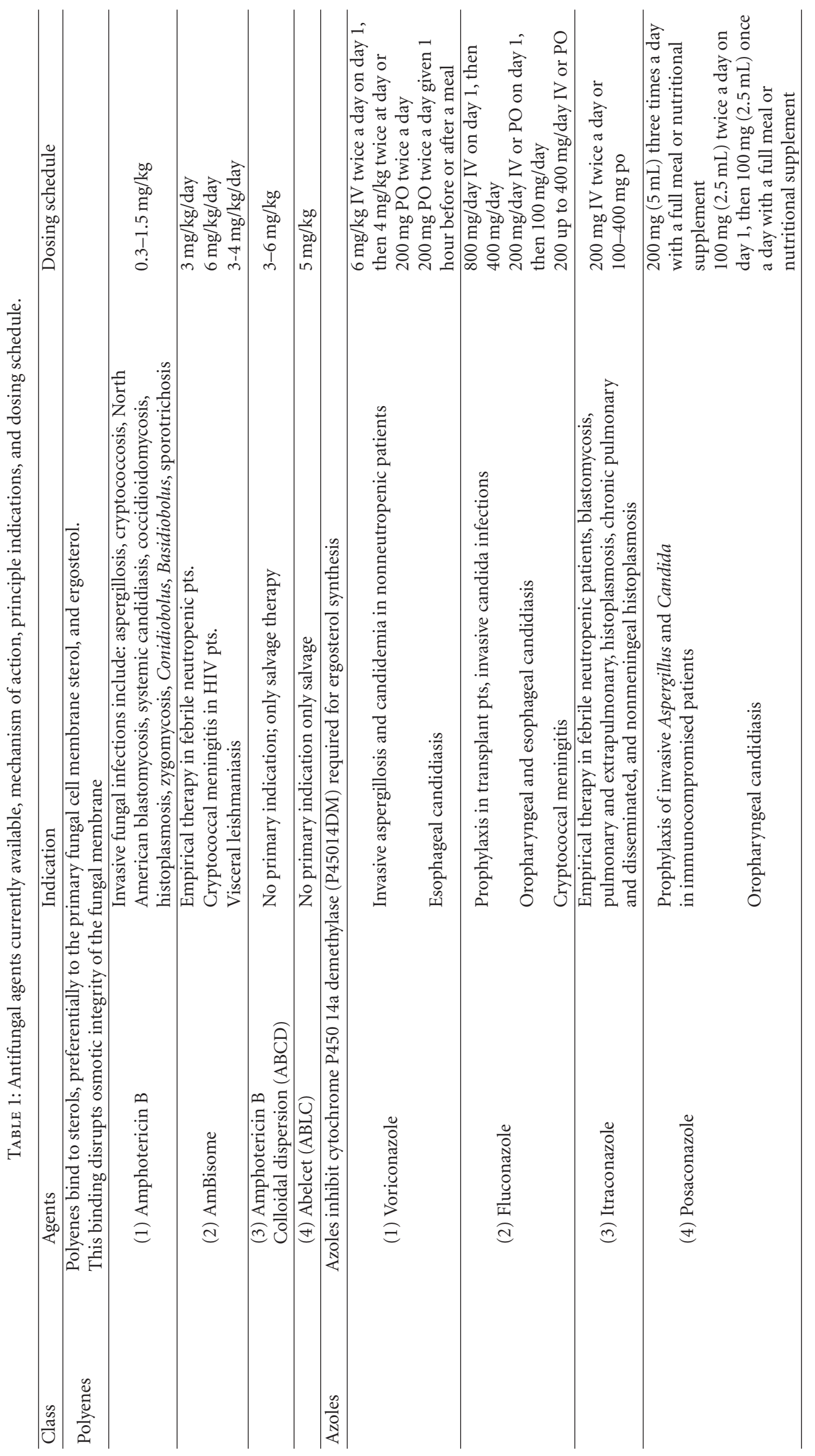




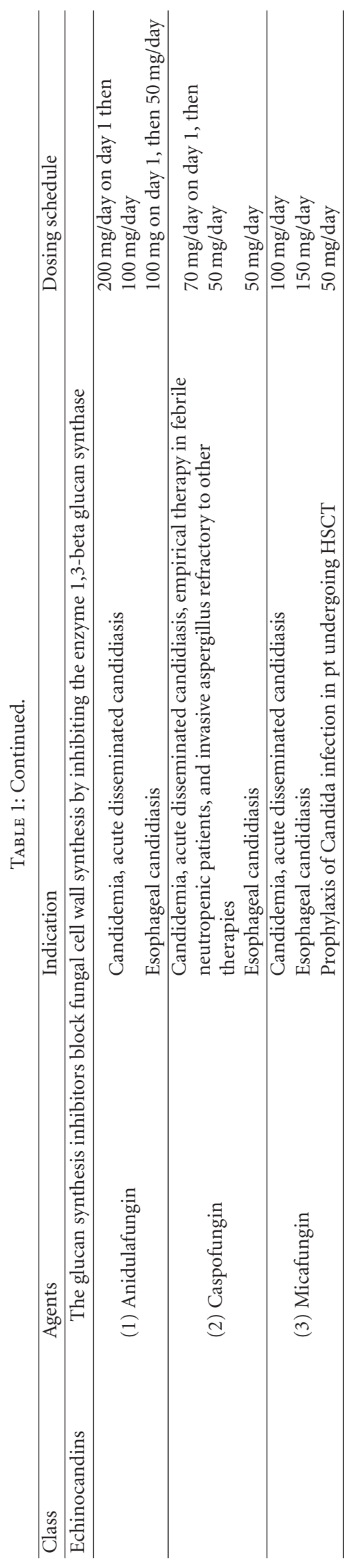


TABLE 2: Pathogenic fungi and the antifungal agents in vitro activity**.

\begin{tabular}{|c|c|c|c|c|c|}
\hline \multirow{2}{*}{ Microorganism } & \multicolumn{5}{|c|}{ Antifungal agents } \\
\hline & Fluconazole & Voriconazole & Posaconazole & Echinocandin & Polyenes \\
\hline Candida albicans & 1st line & 1st line & 1st line & 1st line & 1st line \\
\hline Candida glabrata & Unknown & 3rd line & 3rd line & 1st line & 2nd line \\
\hline Candida tropicalis & 1st line & 1st line & 1st line & 1st line & 1st line \\
\hline Candida parapsilosis & 1st line & 1st line & 1st line & 2nd line & 1st line \\
\hline Candida krusei & No activity & 2nd line & 2nd line & 1st line & 2nd line \\
\hline Candida guilliermondii & 1st line & 1st line & 1st line & 2nd line & 2nd line \\
\hline Candida lusitaniae & 3rd line & 2nd line & 2nd line & 2nd line & 2nd line \\
\hline Cryptococcus neoformans & 1st line & 1st line & 1st line & No activity & 1st line \\
\hline Aspergillus fumigatus & No activity & 1st line & 1st line & 2nd line & 2nd line \\
\hline Aserpgillus flavus & No activity & 1st line & 1st line & 2nd line & 2nd line \\
\hline Aspergillus terreus & No activity & 1st line & 1st line & 2nd line & No activity \\
\hline Fusarium sp. & No activity & 2nd line & 2nd line & No activity & 2nd line \\
\hline Scedosporium apiospermum & No activity & 1st line & 1st line & Unknown & Unknown \\
\hline Scedosporium prolificans & No activity & Unknown & Unknown & No activity & Unknown \\
\hline Trichosporon spp. & Unknown & 2nd line & 2nd line & No activity & 3rd line \\
\hline Zygomycetes (e.g., Absidia, Mucor, and Rhizopus) & No activity & No activity & 1st line & No activity & 1st line \\
\hline $\begin{array}{l}\text { Dematiaceous molds } \\
\text { (e.g., Alternaria, Bipolaris, Curvularia, and } \\
\text { Exophiala) }\end{array}$ & Unknown & 1st line & 1st line & 3rd line & 3rd line \\
\hline \multicolumn{6}{|l|}{ Dimorphic Fungi } \\
\hline Blastomyces dermatitidis & 3rd line & 2nd line & 2nd line & No activity & 1st line \\
\hline Coccidioides immitis & 1st line & 2nd line & 2nd line & No activity & 1st line \\
\hline Histoplasma capsulatum & 3rd line & 2nd line & 2nd line & No activity & 1st line \\
\hline Sporothrix schenckii & 3rd line & 2nd line & 2nd line & No activity & 1st line \\
\hline
\end{tabular}

${ }^{* *}$ Echinocandins, voriconazole, posaconazole, and polyenes have poor urine penetration.

Amphotericin is an accepted antifungal agent for $C$. albicans but has reduced activity against C. glabrata, $C$. krusei, C. lusitaniae, and molds. Moreover, polyenes have not been shown to be of any value in prophylaxis. The toxicity of the polyenes, especially their nephrotoxicity and their expense (lipid solubilized polyenes), make them less likely to be used than other currently available agents.

7.2. Azoles. This class of agents is less toxic than the polyenes and can be administered both orally and intravenously. They act by inhibiting ergosterol synthesis and through other unidentified mechanisms. Their perturbation of a large number of P450 enzyme systems limits their use in individuals, who require other agents which are metabolized by P450 enzymes which may mandate an alternative dosing regimen of these other agents (see Tables 3(a) and 3(b)). The superior toxicity profile of fluconazole, its availability in an intravenous and oral formulation, and its low cost make it the agent of choice for hemodynamically stable patients with Candidemia.

The activity of voriconazole against Candida is superior to that achieved with fluconazole based upon MIC data, its activity against fluconazole-resistant species, and its wider spectrum make it the preferred agent for hemodynamically unstable patients or those where the infection is due to a nonalbicans Candida, Aspergillus, or any other mold [37]. It, however, has a clinically important effect on the metabolism of calcineurin inhibiting agent (immunosuppressive agents), resulting in a marked increase in their whole blood levels, which can reach toxic levels unless the dose of these immunosuppressive agents is reduced markedly. Moreover, two unique toxicities have been associated with the use of voriconazole. These are the development of a visual disturbance and cutaneous photosensitivity. The visual disturbance occurs in as many as $45 \%$ of individuals receiving the agent. Typically, it is transient and resolves with continued treatment. The cutaneous photosensitivity reaction is unusual and importantly is not prevented with sun-screen lotions. It is fully reversible with drug discontinuation. The use of voriconazole and posaconazole is contraindicated when sirolimus is being utilized as part of the immune suppressive regimen (see Table 3(a)). Itraconazole can cause a unique complex of adverse effects consisting of hypotension, hypokalemia, and edema. A negative inotropic effect causing congestive heart failure has been identified as well and limits its usefulness in individuals with preexisting heart disease [38]. Itraconazole has two other limiting issues 


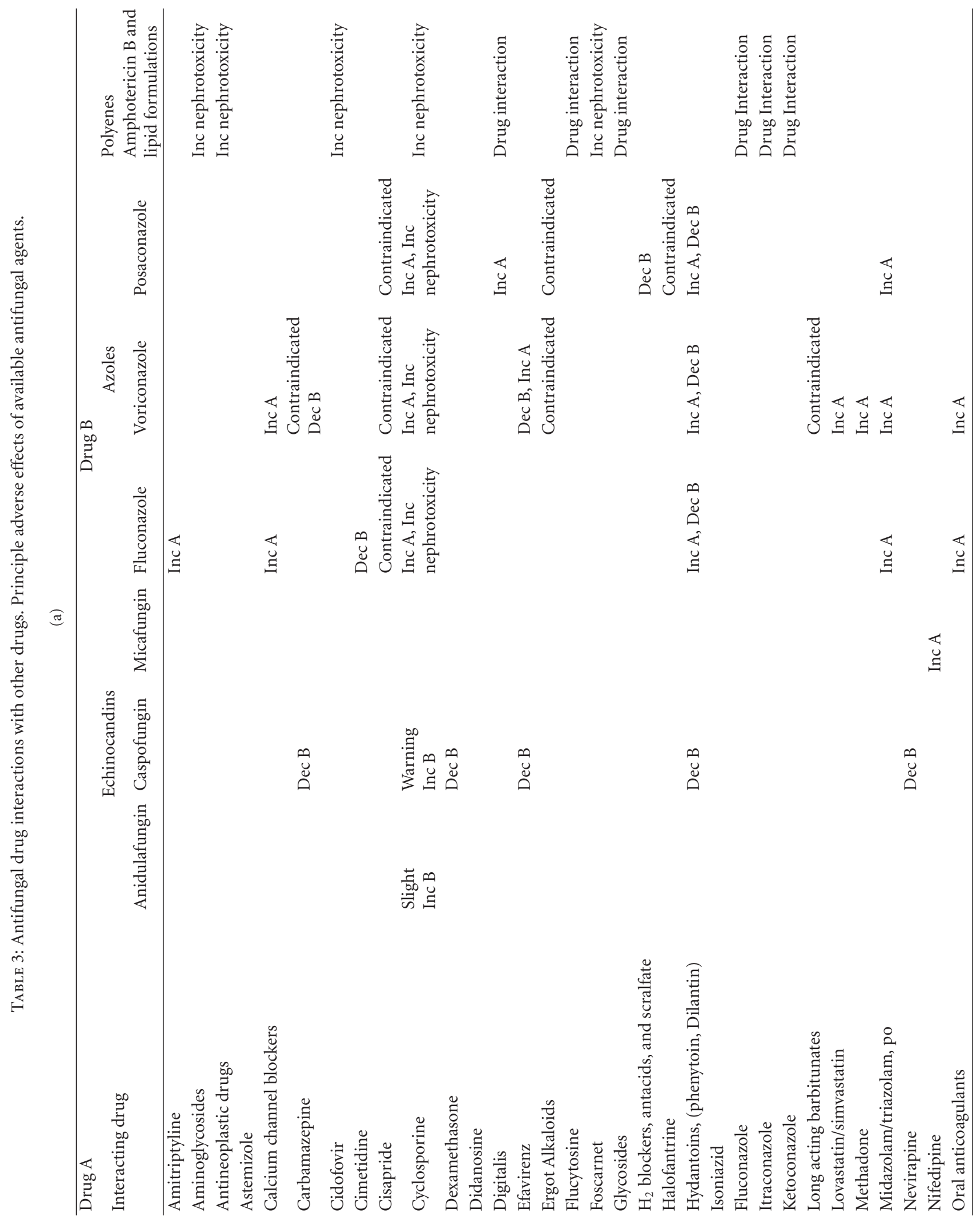




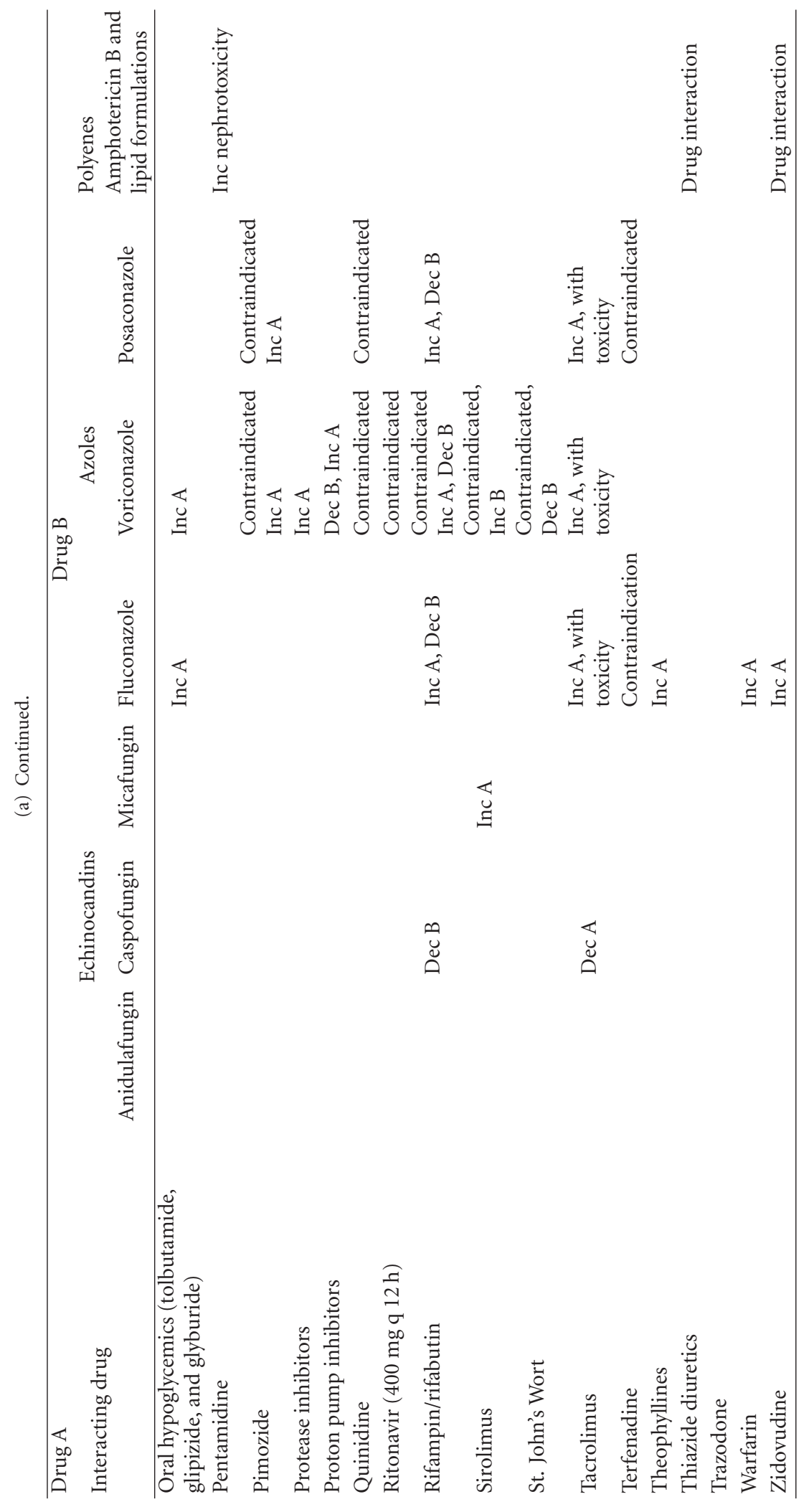




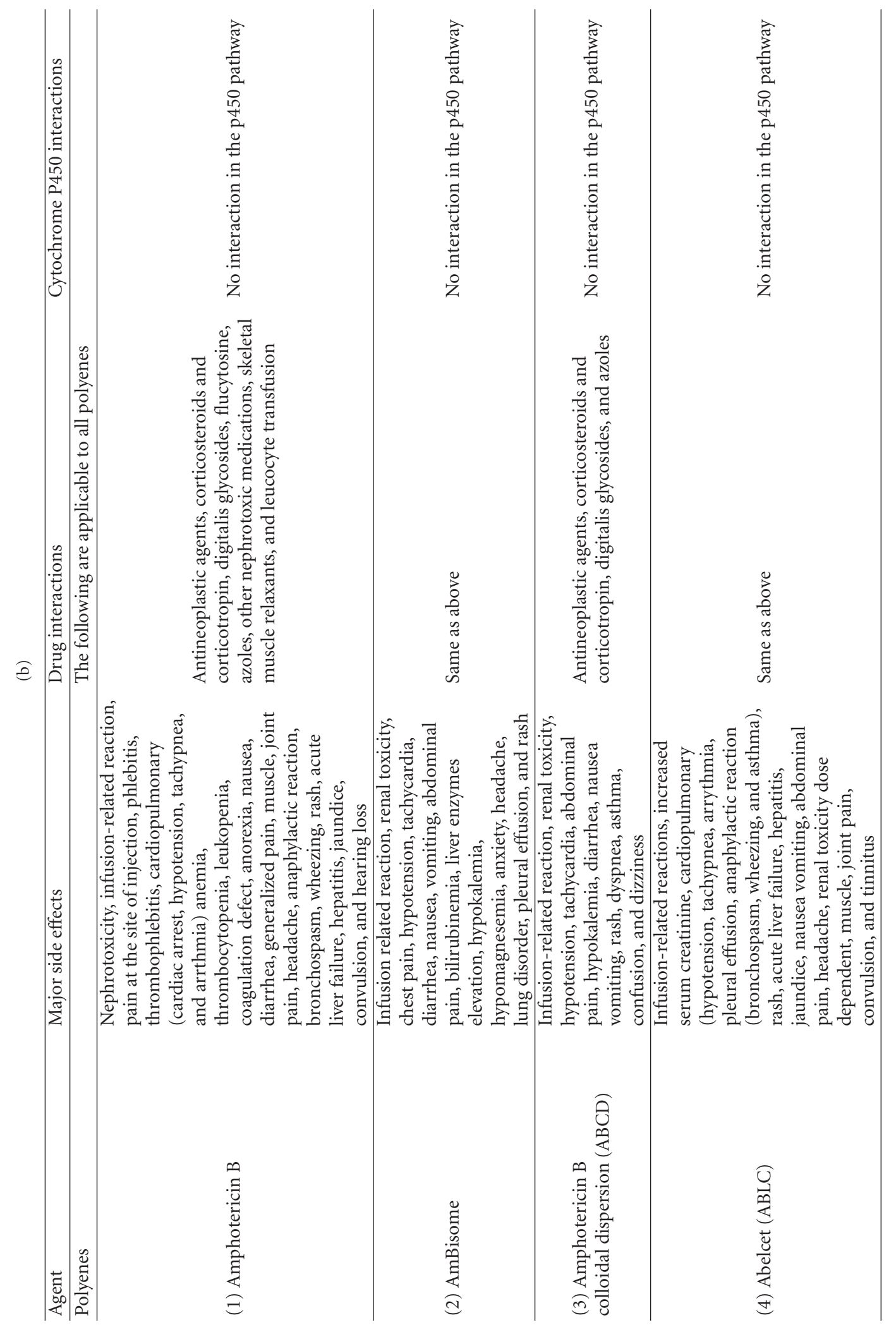




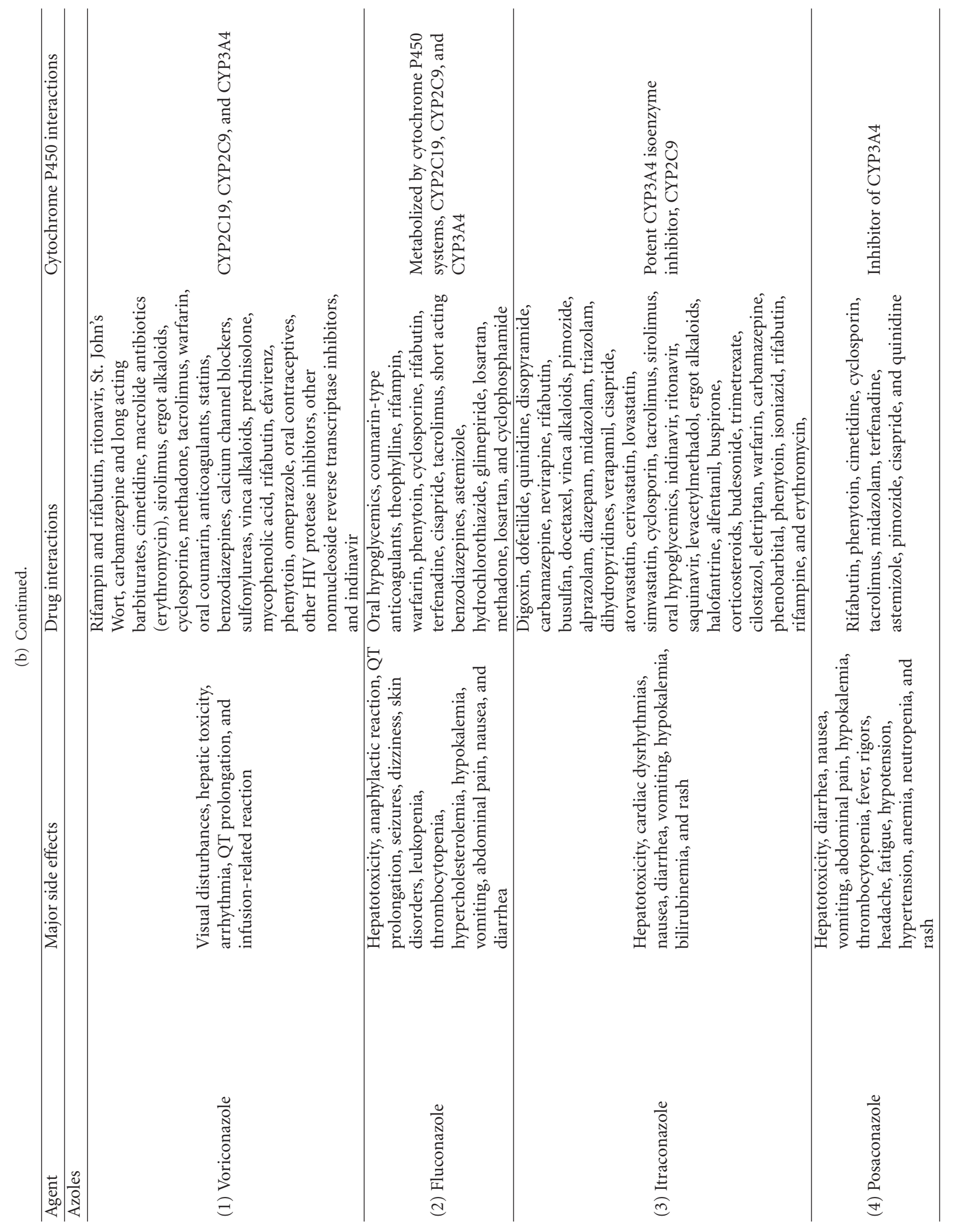




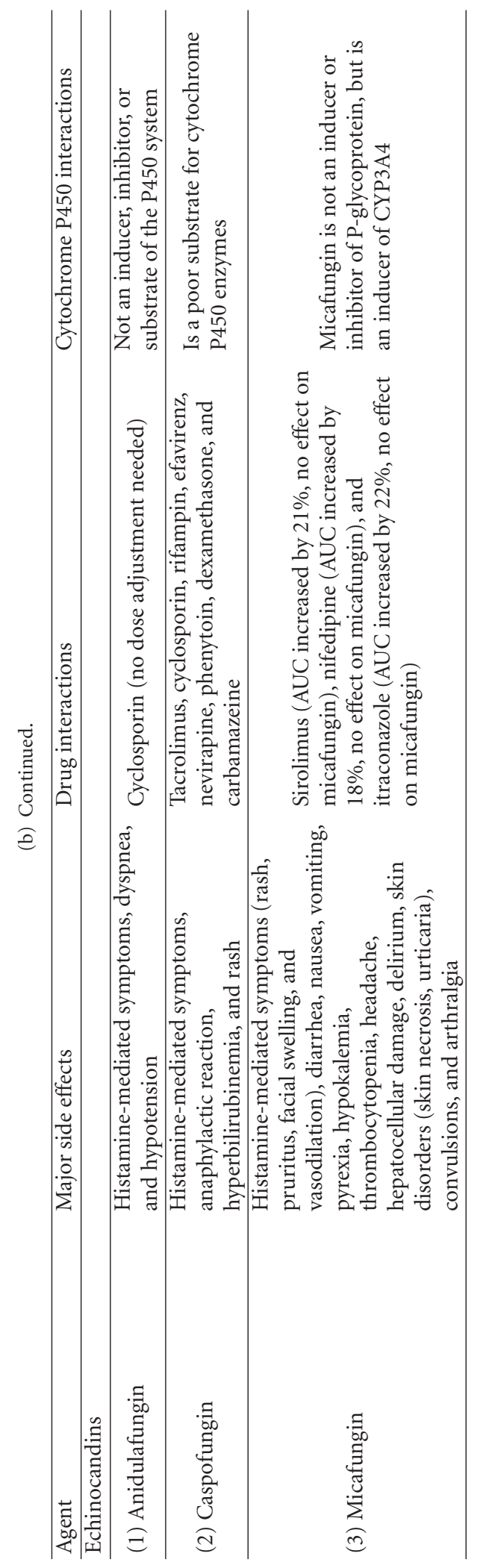


TABLE 4: Current contraindications and FDA warnings for each antifungal agent available.

\begin{tabular}{|c|c|c|}
\hline Drug & Contraindications & Warnings \\
\hline Amphotericin B deoxycholate & Hypersensitivity to amphotericin B & Anaphylaxis \\
\hline Lipid formulations of AMB & Hypersensitivity to amphotericin B & Anaphylaxis \\
\hline Fluconazole & Hypersensitivity to fluconazole & $\begin{array}{l}\text { Hepatic injury, anaphylaxis, and } \\
\text { dermatologic }\end{array}$ \\
\hline Itraconazole & $\begin{array}{l}\text { Terfenadine, astemizole, dofetilide, } \\
\text { pimozide, quinidine, oral midazolam, } \\
\text { triazolam, cisapride, and statins should also } \\
\text { be discontinued during therapy }\end{array}$ & $\begin{array}{l}\text { Black box for terfenadine and congestive } \\
\text { Heart failure see contraindications }\end{array}$ \\
\hline Posaconazole & $\begin{array}{l}\text { Hypersensitivity to the active substance or } \\
\text { excipients, ergot alkaloids, coadministration } \\
\text { with } 3 \mathrm{~A} 4 \text { substrates (terfenadine, } \\
\text { astemizole, cisapride, pimozide, } \\
\text { halofantrine, and quinidine) }\end{array}$ & $\begin{array}{l}\text { Hypersensitivity, hepatic toxicity, } \\
\text { recommended monitoring of hepatic } \\
\text { function (LFTs), cyclosporine, tacrolimus, } \\
\text { and sirolimus }\end{array}$ \\
\hline Voriconazole & $\begin{array}{l}\text { Hypersensitivity to voriconazole, CYP3A4 } \\
\text { inhibitors (terfenadine, astemizole, } \\
\text { cisapride, pimozide, and quinidine), } \\
\text { sirolimus, rifampin, carbamezapine, long } \\
\text { acting barbiturates, ritonavir, efavirenz, } \\
\text { rifabutin, and ergot alkaloids (ergotamine } \\
\text { and dihydroergotamine) }\end{array}$ & $\begin{array}{l}\text { Visual disturbances, hepatic toxicity, } \\
\text { recommended monitoring of LFTs and } \\
\text { bilirubin, pregnancy category D, and } \\
\text { galactose intolerance }\end{array}$ \\
\hline Anidulafungin & $\begin{array}{l}\text { Hypersensitivity to anidulafungin or other } \\
\text { echinocandins }\end{array}$ & None \\
\hline Caspofungin & $\begin{array}{l}\text { Hypersensitivity to caspofungin or other } \\
\text { echinocandins }\end{array}$ & Elevated liver enzymes with cyclosporine \\
\hline Micafungin & $\begin{array}{l}\text { Hypersensitivity to micafungin or other } \\
\text { echinocandins }\end{array}$ & $\begin{array}{l}\text { Hypersensitivity, hematological effects } \\
\text { (hemolysis, hemolytic anemia, and } \\
\text { hemoglobinuria), hepatic effects (abnormal } \\
\text { LFTs, hepatic dysfunction, hepatitis, and } \\
\text { hepatic failure), and renal effects (elevations } \\
\text { of BUN and creatinine, renal dysfunction, } \\
\text { and acute renal failure) }\end{array}$ \\
\hline
\end{tabular}

TABLE 5: Pharmacokinetic parameters of the major echinocandins in clinical use*.

\begin{tabular}{lccccccc}
\hline Agent & $C_{\max }$ & $t_{1 / 2}$ & $V_{d}$ & AUC & $C_{t}$ & FeU & FeS \\
\hline Caspofungin & 7.64 & 10 & 0.4 & $88-115$ & 0.15 & $1.40 \%$ & $35 \%$ \\
Micafungin & 4.95 & 14 & 0.23 & 111 & 0.19 & $0.70 \%$ & $40 \%$ \\
Anidulafungin & $2.07-3.5$ & 25 & 0.5 & $44-53$ & 0.26 & $<1 \%$ & $30 \%,<10 \%$ unchanged \\
\hline
\end{tabular}

${ }^{*}$ Dose $50 \mathrm{mg}$ single dose, $C_{\max }$ : maximum concentration, $t_{1 / 2}$ : elimination half-life, $V_{d}$ : volume of distribution, AUC: area under the plasma concentration and time curve, $C_{t}$ : total clearance, FeU: fraction excreted in urine, FeS: fraction excreted in stool.

particularly in hematopoietic stem-cell transplant patients: its potential for hepatotoxicity and its reduced absorption when used in combination with either $\mathrm{H}_{2}$ blockers or proton-pump inhibiting agents.

7.3. Fluorocytosine. Fluorocytosine is a pyrimidine analog that inhibits both DNA and protein synthesis. Its principal use is in combination with other agents for the treatment of cryptococcal infections [39-41].The development of rapid drug resistance and its toxicity pattern (see Table $3(\mathrm{~b})$ ) limits its usefulness in other fungal infections [41].

7.4. Echinocandins. The echinocandins are semisynthetic lipopeptides that were isolated originally from various fungal agents and subsequently modified. Specifically, they are cyclic hexapeptides with an N-linked acyl-side chain that appears to be essential for their antifungal activity. They have different molecular weights that vary around 1200 daltons. This class of agents inhibits glucan synthesis, a major component of the fungal cell wall required for stability, especially in Candida and Aspergillus species. The echinocandins have been shown to enhance phagocytic activity of macrophages, an action that may also contribute to their efficacy in eliminating fungal infections. Moreover, they also have activity against preformed Candida biofilms and thus prevent Candida species from adhering to endothelial cells.

The pharmacokinetic characteristics of the echinocandins are shown in Table 5 . There are very minor differences 
between the various agents except for the precise mechanism of their metabolism. Importantly, no dose adjustments have to be made for patients with renal disease. Currently, anidulafungin is the only available echinocandin that does not require a dose adjustment in cases with moderate liver disease defined as those having Child-Pugh scores between 7 and 9.

Because the echinocandins do not perpetuate cytochrome P450 enzyme systems and they do not interact with P-glycoprotein, as some azoles do, they do not affect the levels of the calcineurin-inhibiting immunosuppressive agents and the many other drugs used to manage other infections, hypertension, and cardiac arrhythmias frequently seen in transplant recipients (Tables 3(a) and 3(b)). Of particular interest to the transplant population, echinocandins have limited theoretical activity against Pneumocystis carinii ( $P$. jiroveci) infections $[42,43]$.

They are efficacious also against the histoplasmosis species, blastomyces species, and coccidioides speciesfungal agents that cause late onset infections in transplant populations.

Resistance to echinocandins has been reported $[44,45]$. Unfortunately, available assessments of MIC values for the echinocandins do not clearly distinguish between sensitive and resistant fungi [37, 45-48]. As a result, these assays have to be interpreted with caution and in context.

The specific mechanisms responsible for resistance to the echinocandins are not clear but appear to be related to mutations in a subunit of glucan synthetase $[44,49]$. Other minor mechanisms have been identified as well.

Elevations of serum transaminase and alkaline phosphatase levels are among the most common laboratory changes associated with caspofungin [50, 51]. Micafungin has recently had its use in patients with liver disease restricted (as noted in its new package insert) because of reports of acute hepatitis and hepatic failure occurring with its application [51]. The use of drugs such as rifampin, phenytoin, carbamezapine, efavirenz, and nevirapine causes a reduction in caspofungin levels and necessitate a 50\% increase its dosage. Caspofungin reduces the AUC for tacrolimus by $20 \%$, while cyclosporine has been reported to cause a $35 \%$ increase in the AUC for caspofungin. Micafungin increases the AUC for sirolimus by $21 \%$ and for nifedipine by $18 \%$. These interactions have not been reported to occur with anidulafungin (Tables $3(\mathrm{a})$ and $3(\mathrm{~b})$ ).

It should be noted that the average wholesale cost of a 20-day course of caspofungin in the United States is approximately $\$ 7-8,000$ as compared to $\$ 3-4,000$ for anidulafungin and $\$ 2-5,000$ for intravenous fluconazole (depending upon the dose). The average wholesale cost for micafungin for the same period would be $\$ 4-5,000$.

\section{Clinical Use of the Available Antifungal Agents}

The agents available for treatment of invasive fungal infections are presented in Tables 1 and 2.
The mechanisms of action of each class of drugs, the specific disease indication for each drug, and the doses that are recommended for each indication are indicated in Table 1.

Table 2 presents data relative to the choice of antifungal therapy for each fungal agent that is currently approved by the FDA. The drug choices are indicated as first line (recommended), second line (less frequently utilized but effective), and third line (potentially having efficacy) and those having unknown efficacy.

Table 3 presents reported efficacy data and overall mortality data achieved when treating systemic fungal infections.

Voriconazole is currently the first line therapy for Aspergillus infections $[52,53]$. Voriconazole is also the only agent indicated for infections due to Fusarium species and Scedosporium apiospermum. Only voriconazole, fluconazole, and itraconazole are available in oral as well as the intravenous formulations. The echinocandins have replaced azole agents for the treatment of invasive candidiasis [52-54].

The principal adverse effects and drug interactions of each antifungal agent are reported in Tables 3(a) and 3(b).

Table 6 lists the contraindications and FDA warnings for the available antifungal agents.

The effect of preexisting renal and/or hepatic dysfunction on the dosing of these available antifungal agents is shown in Tables 6(a) and 6(b). The dose of the azole agents needs to be reduced as the creatinine clearance declines. The effect of preexisting renal disease is inconsequential for the echinocandins. As noted, little data exists for the use of antifungal agents in individuals with hepatic disease. The only agent for which no dose adjustment is required for advanced hepatic disease is anidulafungin [55].

There are four emerging antifungal agents [47]. These include isavuconazole and ravuconazole both of which have a broad spectrum of activity, a large volume of distribution, and very long half-lives. Albaconazole has a broad spectrum of activity against Candida species, Aspergillus species, and Cryptococcus species as well as a long half-life. Aminocandin has a very long half-life enabling the drug to be given intravenously less often than daily.

Combination antifungal therapy is occasionally used in severe and clinically drug-resistant infections in an effort to maximize efficacy and potentially minimize toxicity $[56,57]$. In selecting agents to be used in combination, only those that have different mechanisms of actions should be combined. Thus, the use of an agent acting at the cytoplasmic membrane (a polyene or an azole) plus an agent acting on DNA or protein synthesis (fluorocytosine) or a cell wall active agent (echinocandins) is recommended if combination therapy is to be utilized. It should be noted, however, that there are no definitive data supporting the use of combination therapy in the treatment of fungal infections per se but such can be reasonably implied from the use of combination treatments as an accepted treatment for bacterial and viral infections. This being said, considering the low efficacy rates reported for single agent treatment of invasive fungal infections in general, combination therapy has the potential to increase the efficacy of treatment in difficult-to-treat situations. A single study consists of a triazole and an echinocandin 
TABLE 6

(a) Experience in patients with prexisting renal disease

\begin{tabular}{|c|c|c|}
\hline Agent & Effects on the kidney & Dosing modifications for preexisting renal disease \\
\hline (1) Amphotericin B & $\begin{array}{l}\text { Nephrotoxic-elevation of BUN, } \\
\text { creatinine }\end{array}$ & Sodium loading to ameliorate toxicity \\
\hline (2) AmBisome & Nephrotoxic & Used in pt with pre-existing renal impairment \\
\hline (3) $\mathrm{ABCD}$ & Nephrotoxic & \\
\hline (4) ABLC & Dose-limited renal toxicity & \\
\hline \multirow[t]{2}{*}{ (5) Voriconazole } & SBECD component of iv formulation & $\begin{array}{l}\text { No adjustment for oral vori in pts with mild-to-severe } \\
\text { renal impairment }\end{array}$ \\
\hline & associated with renal toxicity & I.V. should be avoided if creatinine clearance $<30 \mathrm{~mL} / \mathrm{min}$ \\
\hline \multirow[t]{2}{*}{ (6) Fluconazole } & & $\begin{array}{l}50-400 \mathrm{mg} \text { creatinine clearance }>50-100 \% \text { creatinine } \\
\text { clearance }<50 \text { (no dialysis)-adm. } 50 \% \text { of dose }\end{array}$ \\
\hline & & regular dialysis-admin $100 \%$ of dose after each dialysis \\
\hline (7) Itraconazole & $\begin{array}{l}\text { SBECD component of iv formulation } \\
\text { associated with renal toxicity }\end{array}$ & I.V. should not be used if creatinine clearance $<30 \mathrm{~mL} / \mathrm{min}$ \\
\hline (8) Posaconazole & & $\begin{array}{l}\text { No dose adjustment for mild-to-moderate } \\
\text { severe-monitor for breakthrough IFI }\end{array}$ \\
\hline (9) Anidulafungin & None & No dose adjustment, not dialyzable \\
\hline (10) Caspofungin & None & No dose adjustment, not dialyzable \\
\hline (11) Micafungin & None & No dose adjustment \\
\hline
\end{tabular}

(b) Experience in individuals with pre-existing hepatic disease

\begin{tabular}{|c|c|c|c|c|c|}
\hline Antifungal & Normal Patients & $\begin{array}{l}\text { Mild } \\
\text { (Child-Pugh 5-6) }\end{array}$ & $\begin{array}{l}\text { Moderate } \\
\text { (Child-Pugh 7-9) }\end{array}$ & $\begin{array}{l}\text { Severe } \\
(\text { Child-Pugh }>9)\end{array}$ & Effects on the liver \\
\hline Anidulafungin & $\begin{array}{l}200 \mathrm{mg} \text { loading } \\
\text { dose on day } 1 \\
\text { followed by } 100 \mathrm{mg} \\
\text { once/day }\end{array}$ & $\begin{array}{l}200 \mathrm{mg} \text { loading } \\
\text { dose on day } 1 \\
\text { followed by } 100 \mathrm{mg} \\
\text { once/day }\end{array}$ & $\begin{array}{l}200 \mathrm{mg} \text { loading } \\
\text { dose on day } 1 \\
\text { followed by } 100 \mathrm{mg} \\
\text { once/day }\end{array}$ & $\begin{array}{l}200 \text { mg loading } \\
\text { dose on day } 1 \\
\text { followed by } 100 \\
\text { mg once/day }\end{array}$ & None \\
\hline Micafungin & $100 \mathrm{mg}$ once/day & $100 \mathrm{mg}$ once/day & $100 \mathrm{mg}$ once/day & Not studied & None \\
\hline Caspofungin & $\begin{array}{l}70 \mathrm{mg} \text { loading dose } \\
\text { on day } 1 \text { followed } \\
\text { by } 50 \mathrm{mg} \text { once/day }\end{array}$ & $\begin{array}{l}70 \mathrm{mg} \text { loading dose } \\
\text { on day } 1 \text { followed } \\
\text { by } 50 \mathrm{mg} \text { once/day }\end{array}$ & $\begin{array}{l}70 \mathrm{mg} \text { loading dose } \\
\text { on day } 1 \text { followed } \\
\text { by } 35 \mathrm{mg} \text { once/day }\end{array}$ & Not studied & None \\
\hline Fluconazole & $\begin{array}{l}\text { Loading dose of } 2 \mathrm{x} \\
\text { the daily dose, then } \\
\text { up to } 400 \mathrm{mg} \text { daily }\end{array}$ & $\begin{array}{l}\text { No dosage adjustme } \\
\text { worsening hepatic fu }\end{array}$ & $\begin{array}{l}\text { ents initially, monitor } \\
\text { unction }\end{array}$ & LFTs in patients for & Hepatotoxic \\
\hline Itraconazole & $\begin{array}{l}200 \mathrm{mg} \text { q12 IV } \\
100-200 \mathrm{mg} \text { q12 } \\
\text { po-solution }\end{array}$ & $\begin{array}{l}\text { No studies have beer } \\
\text { impairment, use wit }\end{array}$ & $\begin{array}{l}\text { n conducted looking } \\
\text { th caution }\end{array}$ & at patients with hepatic & $\begin{array}{l}\text { Hepatotoxic, prolonged } \\
\text { elimination half-life in } \\
\text { cirrhotic patients (meds } \\
\text { metabolized by CYP3A4) }\end{array}$ \\
\hline Voriconazole & $\begin{array}{l}6 \mathrm{mg} / \mathrm{kg} \text { IV q12h } \\
\text { for the first } \\
24 \text { hours loading } \\
\text { dose followed by } \\
3-4 \mathrm{mg} / \mathrm{kg} \text { IV q12h } \\
\text { maintenance dose } \\
\text { then } 200 \mathrm{mg} \text { q12h } \\
\text { oral }\end{array}$ & $\begin{array}{l}6 \mathrm{mg} / \mathrm{kg} \text { IV q12h } \\
\text { for the first } \\
24 \text { hours loading } \\
\text { dose followed by } \\
1.5-2 \mathrm{mg} / \mathrm{kg} \text { IV } \\
\text { q12h maintenance } \\
\text { dose }\end{array}$ & $\begin{array}{l}6 \mathrm{mg} / \mathrm{kg} \mathrm{IV} \mathrm{q12h} \\
\text { for the first } \\
24 \text { hours loading } \\
\text { dose followed by } \\
1.5-2 \mathrm{mg} / \mathrm{kg} \text { IV } \\
\text { q12h maintenance } \\
\text { dose }\end{array}$ & Not studied & Hepatotoxic \\
\hline Posaconazole & $\begin{array}{l}\text { Oral Suspension } \\
200 \mathrm{mg}(5 \mathrm{~mL}) \\
\text { three times a day } \\
\text { with a full meal or } \\
\text { liquid nutritional } \\
\text { supplement, } \\
\text { monitoring of } \\
\text { LFT's is } \\
\text { recommended }\end{array}$ & \multicolumn{3}{|c|}{$\begin{array}{l}\text { Data was not sufficient to determine dosing, should be used with } \\
\text { caution }\end{array}$} & $\begin{array}{l}\text { Mild-to-moderate } \\
\text { elevation of liver enzymes, } \\
\text { bilirubin-generally } \\
\text { reversible }\end{array}$ \\
\hline
\end{tabular}


(b) Continued.

\begin{tabular}{|c|c|c|c|c|c|}
\hline Antifungal & Normal Patients & $\begin{array}{l}\text { Mild } \\
\text { (Child-Pugh 5-6) }\end{array}$ & $\begin{array}{l}\text { Moderate } \\
\text { (Child-Pugh 7-9) }\end{array}$ & $\begin{array}{l}\text { Severe } \\
(\text { Child-Pugh >9) }\end{array}$ & Effects on the liver \\
\hline $\begin{array}{l}\text { Amphotericin B } \\
\text { deoxycholate }\end{array}$ & 0.6 to $1 \mathrm{mg} / \mathrm{kg} /$ day & \multicolumn{3}{|c|}{ Data was not sufficient to determine dosing } & Elevation of liver enzymes \\
\hline $\begin{array}{l}\text { Ampho B lipid } \\
\text { complex (Abelcet) }\end{array}$ & $5 \mathrm{mg} / \mathrm{kg} /$ day & \multicolumn{3}{|c|}{ Data was not sufficient to determine dosing } & Elevation of liver enzymes \\
\hline $\begin{array}{l}\text { Ampho B colloidal } \\
\text { dispersion } \\
\text { (Amphotec) }\end{array}$ & $\begin{array}{l}3-4 \mathrm{mg} / \mathrm{kg} / \text { day can } \\
\text { be increased up to } \\
6 \mathrm{mg} / \mathrm{kg} / \text { day }\end{array}$ & \multicolumn{3}{|c|}{ Data was not sufficient to determine dosing } & Elevation of liver enzymes \\
\hline $\begin{array}{l}\text { Ampho B liposomal } \\
\text { (AmBisome) }\end{array}$ & $\begin{array}{l}3-4 \mathrm{mg} / \mathrm{kg} / \text { day can } \\
\text { be increased up to } \\
6 \mathrm{mg} / \mathrm{kg} / \text { day }\end{array}$ & \multicolumn{3}{|c|}{ Data was not sufficient to determine dosing } & Elevation of liver enzymes \\
\hline
\end{tabular}

in solid organ transplant recipients. It shows a reduction in mortality in individuals with renal failure and invasive Aspergillus [56].

\section{Clinical and Economic Relevance of Fungal Infections, Particularly Candidiasis}

In the past, systemic fungal infections have been considered to be a problem only for neutropenic patients. However, beyond the risk factor of neutropenia, more recent data suggests that half of all hospital-acquired fungal infections have occurred in critically-ill surgical patients.

Candida species account for greater than $80 \%$ of all fungal nosocomial isolates [62-64] unlike Aspergillus species and the less common Fusarium and Rhizopus species which comprise only $10 \%$ of the remaining nosocomial isolates. Invasive candidiasis is the most frequently occurring invasive fungal infection and occurs most commonly in immunocompromised solid organ transplant recipients, those receiving chemotherapy, and those having multiple, complex abdominal surgical procedures.

As stated earlier, Candida species have become the fourth most common nosocomial bloodstream isolate, exceeded only by coagulase negative Staphylococcus, Staphylococcus aureus, and Enterococci. This fact is particularly important when it is recognized that less than half of these cases with invasive Candidemia documented at autopsy have had a positive premortem blood culture for Candida [59].

Invasive Candida infections have a mortality rate averaging between 25 and 38\%. The specific Candida species accounting for Candidemia in high-risk populations have shifted over the last decade from C. albicans to more nonalbicans species, with approximately half the reported cases being due to the nonalbicans species [5]. More importantly these nonalbicans species (C. glabrata, C. krusei, and C. parapsilosis) have a greater mortality rate, account for the greater length of stay in ICUs, and are associated with greater rates of renal failure, thrombocytopenia, malignancy, and mechanical ventilation. The risk factors recognized for Candidemia in general include complicated abdominal operations, second operations, parenteral nutrition, the use of broad-spectrum antibiotics, the use of multiple vascular catheters, prior recognized Candida colonization, mechanical ventilation, and renal replacement therapy $[58,59]$.

In a prospective clinical trial examining the risk factors for Candida bloodstream infections in more than 4,000 surgical patients, those identified included previous surgery $(\mathrm{RR}=7.3)$, acute renal failure $(\mathrm{RR}=4.2)$, parenteral nutrition $(\mathrm{RR}=3.6)$, and the presence of a triple lumen catheter $(\mathrm{RR}=5.4)[58]$. Other risk factors identified in other studies included ICU hospitalization $>4$ days, diabetes mellitus, HIV infections, central lines, neutropenia, chemotherapy, cancer (especially hematologic cancers), use of broad-spectrum antibiotics, the use of 3 or more antibiotics, and mechanical ventilation $>2$ days.

The initial response to a suspected Candidemia is to institute antifungal therapy with either voriconazole or an echinocandin and the removal of all vascular lines. It is important to recognize that blood cultures are positive in cases of invasive Candidemia in less than $50 \%$ of the time. Invasive Fusarium infections, similar to Candida infections, are detectable with blood culture in less than half of the cases. Worse invasive Aspergillus infections are rarely identifiable with blood cultures.

First line therapy for Candidemia remains controversial as studies have reported similar efficacy rates with amphotericin, fluconazole, echinocandins, and voriconazole [6569]. With the increasing frequency of nonalbicans species especially in critically-ill patients the use of a broad-spectrum agent such as voriconazole, an echinocandin, or amphotericin may be more appropriate at least until the specific Candida species is identified to avoid the increased mortality occurring in cases wherein an inappropriate therapeutic agent is initially started. The limitation of intravenous voriconazole is its formulation with cyclodextrin which accumulates in individuals with impaired renal function. The many adverse effects of amphotericin identified earlier limit its use. Among the echinocandins, only anidulafungin has shown superiority over fluconazole [55]. Moreover, its efficiency, safety, and lack of cytochrome P450 metabolism suggest that it should be considered as a first line option for invasive candidiasis infection. Regardless of the choice of a specific echinocandin over fluconazole, echinocandins are recommended for use in individuals who are either critically ill or hemodynamically unstable. 
Candidemia is associated with an increased cost of hospitalization estimated at \$68,311 (95\% CI \$57,513$\$ 79,108$ ) and longer length of stay estimated at 23.1 days of hospitalization (95\% CI 19.3-26.8 days) as compared to that of a DRG identified control population without Candidemia [70-72].

The incidence of invasive fungal infections in solid organ transplant recipients ranges from 5-42\% [73]. Depending upon the organ being transplanted, being lowest for pancreas recipients and greatest for liver graft recipients. Candida species, and to a lesser degree Aspergillus, account for the vast majority of invasive fungal agents in solid organ transplant recipients [14]. Cryptococcus and endemic mycoses occur late, typically a year or more after transplantation.

Currently, most liver transplant centers use antifungal prophylaxis in the early postoperative period in individual recipients having either a complicated or repetitive posttransplant surgical procedures [74-76]. The principal problem associated with the use of azole therapy in transplant recipients is the interaction with calcineurin inhibitor agents that consequently requires a dose adjustment in one or the other agents.

\section{Experience with Antifungal Agents in Individuals with Liver Disease}

Although considerable data exists relative to the use and precautions to be utilized with antifungal agents in individuals with advanced renal disease, little data exist for those with advanced liver disease (Tables 6(a) and 6(b)).

At Barnes Jewish Hospital, anidulafungin has recently been utilized instead of the hospital preferred agent caspofungin in two specific disease categories with clinical efficacy [55]. The subjects in this report consisted of those with hepatic dysfunction (71\% of the group) and those with potential drug interactions with caspofungin $(21 \%$ of the group). These two groups were not mutually exclusive however with 4 patients with both criteria. Together, the two groups accounted for $83 \%$ of those receiving anidulafungin in the report.

The authors noted in their discussion that neither caspofungin nor micafungin have been studied in patients with severe liver disease and that anidulafungin is the only agent with suitable pharmacokinetic properties making it an acceptable agent in the liver disease population. In fact, 5 of the 35 patients $(14.5 \%)$ in their study had a total bilirubin level greater than $10 \mathrm{mg} / \mathrm{dL}$ with two having a total bilirubin greater than $40 \mathrm{mg} / \mathrm{dL}$. One of their patients had a transaminase level greater than 10 times the upper level of normal at the time when anidulafungin therapy was initiated.

Fungal infections following liver transplantation although infrequently increase the mortality rate and increase the overall cost of the perioperative transplant care [70-73]. The incidence of drug-resistant C. albicans, nonalbicans Candida species, Aspergillus, and other invasive molds in transplant recipients is increasing and is associated with a reduced survival rate $[77,78]$. Risk factors for fungal infections following liver transplantation are well recognized and include preoperative renal failure, fulminant hepatic failure, prolonged preoperative hospitalization particularly in an intensive care unit, an excessive intraoperative transfusion requirement, early retransplantation or complications requiring a return to the operative theater, and the number of reoperations $[73,75,77]$.

Despite this information, fungal prophylaxis has been a topic of considerable debate in terms of its efficacy, costs, choice of agents, the dose regimen, and the duration of therapy. Recently, failure to provide prophylaxis to a highrisk population of liver transplant recipients was associated with a 4 -fold greater risk of fungal infections $(P<0.05)$ compared to an amphotericin prophylactic risk group [7981].

Only a handful of well-designed prophylactic studies in liver transplant patients have been performed [82-88]. One study was inconclusive while two showed efficacy with fluconazoles in preventing invasive candidiasis. In particular, one study showed that fluconazole prevented infections due to C. albicans but not C. glabrata or C. krusei infections. A single report of the use of itraconazole used prophylactically posttransplant reduced the rate of fungal infections from a control value of $24 \%$ to $4 \%$ [86].

A meta-analysis of the use of antifungal prophylaxis in liver transplant recipients concluded that prophylaxis reduced the total number of episodes of infections as well as the morbidity directly related to the fungal infection but did not affect overall mortality [74].

No prophylactic studies in solid organ transplant recipients have demonstrated a clear beneficial effect at preventing invasive Aspergillus, but have been interpreted as suggesting such might be the case [75-77].

In contrast, studies of targeted therapy after liver transplantation have demonstrated voriconazole as the initial therapy of choice for invasive Aspergillus. Continuous infusions of amphotericin have also been shown to be effective and generally safe, but the many potential effects of amphotericin make voriconazole the preferred agent for this indication $[36,52]$.

\section{Summary}

(1) Fungal infections, especially candidiasis and Aspergillus, are major health problems in seriously ill patients such as transplant recipients, despite the fact that the risk factors for such infections are well recognized and predictable.

(2) Systemic fungal infections are typically diagnosed late and treatment is costly in terms of lives lost, hospital length of stay, and overall medical costs.

(3) Despite a plethora of agents currently available for the treatment of systemic fungal infections, the efficacy of such treatments is low.

(4) Anticipatory or prophylactic therapy of fungal infections in individual patients with 3 or more risk factors for such infections would appear to be prudent and may be the only way that these infections can be prevented. Clearly, further study is necessary to 
determine the best agent, optimal dosing, and duration of therapy in immunosuppressed and transplant patients.

(5) Finally, as these agents are typically used in transplant patients with preexisting disease states, who are on a host of other therapeutic agents for comorbid disease states involving either the kidneys or the liver or both organs, the choice of the antifungal agent to be used in a particular case should be (a) the likelihood of therapeutic benefit, (b) the recognized and anticipated adverse events associated with their use, (c) the potential for drug-drug interactions, and, finally, their ease of administration with particular attention to their use in individuals with preexisting or concurrent renal and/or hepatic disease.

\section{References}

[1] R. V. Fleming, T. J. Walsh, and E. J. Anaissie, "Emerging and less common fungal pathogens," Infectious Disease Clinics of North America, vol. 16, no. 4, pp. 915-933, 2002.

[2] J. H. Rex, T. J. Walsh, and E. J. Anaissie, "Fungal infections in iatrogenically compromised hosts," Advances in Internal Medicine, vol. 43, pp. 321-371, 1998.

[3] H. Wisplinghoff, T. Bischoff, S. M. Tallent, H. Seifert, R. P. Wenzel, and M. B. Edmond, "Nosocomial bloodstream infections in US hospitals: analysis of 24,179 cases from a prospective nationwide surveillance study," Clinical Infectious Diseases, vol. 39, no. 3, pp. 309-317, 2004.

[4] M. M. McNeil, S. L. Nash, R. A. Hajjeh et al., "Trends in mortality due to invasive mycotic diseases in the United States, 1980-1997," Clinical Infectious Diseases, vol. 33, no. 5, pp. 641647,2001

[5] G. Dimopoulos, F. Ntziora, G. Rachiotis, A. Armaganidis, and M. E. Falagas, "Candida albicans versus non-albicans intensive care unit-acquired bloodstream infections: differences in risk factors and outcome," Anesthesia and Analgesia, vol. 106, no. 2, pp. 523-529, 2008.

[6] R. V. Fleming, T. J. Walsh, and E. J. Anaissie, "Emerging and less common fungal pathogens," Infectious Disease Clinics of North America, vol. 16, no. 4, pp. 915-933, 2002.

[7] D. R. Hospenthal, "Uncommon fungi," in Mandell, Douglas, and Bennett's Principles and Practice of Infectious Diseases, G. L. Mandell, J. E. Bennett, and R. Dolin, Eds., vol. 2, pp. 3068-3079, Churchill Livingstone, Philadelphia, Pa, USA, 6th edition, 2005.

[8] A. H. Groll and T. J. Walsh, "Uncommon opportunistic fungi: new noscocomial threats," Clinical Microbiology and Infection, vol. 7, supplement 2, pp. 8-24, 2001.

[9] T. J. Walsh, E. J. Anaissie, D. W. Denning et al., "Treatment of aspergillosis: clinical practice guidelines of the infectious diseases society of America," Clinical Infectious Diseases, vol. 46, no. 3, pp. 327-360, 2008.

[10] N. Singh and D. L. Paterson, "Aspergilus infections in transplant recipients," Clinical Microbiology Reviews, vol. 18, pp. 44-69, 2005.

[11] K. A. Marr, R. A. Carter, F. Crippa, A. Wald, and L. Corey, "Epidemiology and outcome of mould infections in hematopoietic stem cell transplant recipients," Clinical Infectious Diseases, vol. 34, no. 7, pp. 909-917, 2002.

[12] T. Fukuda, M. Boeckh, R. A. Carter et al., "Risks and outcomes of invasive fungal infections in recipients of allogeneic hematopoietic stem cell transplants after nonmyeloablative conditioning," Blood, vol. 102, no. 3, pp. 827-833, 2003.

[13] T. J. Walsh, J. Hiemenz, and P. A. Pizzo, "Editorial response: evolving risk factors for invasive fungal infections-all neutropenic patients are not the same," Clinical Infectious Diseases, vol. 18, no. 5, pp. 793-798, 1994.

[14] N. Singh, "Antifungal prophylaxis for solid organ transplant recipients: seeking clarity amidst controversy," Clinical Infectious Diseases, vol. 31, no. 2, pp. 545-553, 2000.

[15] J. R. Perfect, G. M. Cox, J. Y. Lee et al., "The impact of culture isolation of Aspergillus species: a hospital-based survey of aspergillosis," Clinical Infectious Diseases, vol. 33, no. 11, pp. 1824-1833, 2001.

[16] E. J. Dasbach, G. M. Davies, and S. M. Teutsch, "Burden of aspergillosis-related hospitalizations in the United States," Clinical Infectious Diseases, vol. 31, no. 6, pp. 1524-1528, 2000.

[17] J. A. Fishman, "Overview: fungal infections in the transplant patient," Transplant Infectious Disease, vol. 4, supplement 3, pp. 3-11, 2002.

[18] N. Singh, R. K. Avery, P. Munoz et al., "Trends in risk profiles for and mortality associated with invasive aspergillosis among liver transplant recipients," Clinical Infectious Diseases, vol. 36, no. 1, pp. 46-52, 2003.

[19] L. S. Wilson, C. M. Reyes, M. Stolpman, J. Speckman, K. Allen, and J. Beney, "The direct cost and incidence of systemic fungal infections," Value in Health, vol. 5, no. 1, pp. 26-34, 2002.

[20] R. Zaragoza, J. Pemán, M. Salavert et al., "Multidisciplinary approach to the treatment of invasive fungal infections in adult patients. Prophylaxis, empirical, preemptive or targeted therapy, which is the best in the different hosts?" Therapeutics and Clinical Risk Management, vol. 4, no. 6, pp. 1261-1280, 2008.

[21] M. A. Mennink-Kersten, R. R. Klont, A. Warris, H. J. M. Op Den Camp, and P. E. Verweij, "Bifidobacterium lipoteichoic acid and false ELISA reactivity in aspergillus antigen detection," The Lancet, vol. 363, no. 9405, pp. 325-327, 2004.

[22] J. Maertens, J. Verhaegen, K. Lagrou, J. Van Eldere, and M. Boogaerts, "Screening for circulating galactomannan as a noninvasive diagnostic tool for invasive aspergillosis in prolonged neutropenic patients and stem cell transplantation recipients: a prospective validation," Blood, vol. 97, no. 6, pp. 1604-1610, 2001.

[23] P. E. Marik, "Fungal infections in solid organ transplantation," Expert Opinion on Pharmacotherapy, vol. 7, no. 3, pp. 297-305, 2006.

[24] J. D. Perkins, "Use of aspergillus galactomannan enzymelinked immunosorbent assay (ELISA) in liver transplant patients," Liver Transplantation, vol. 13, no. 2, pp. 304-305, 2007.

[25] C. D. Pfeiffer, J. P. Fine, and N. Safdar, "Diagnosis of invasive aspergillosis using a galactomannan assay: a meta-analysis," Clinical Infectious Diseases, vol. 42, no. 10, pp. 1417-1427, 2006.

[26] W. Meersseman, K. Lagrou, J. Maertens et al., "Galactomannan in bronchoalveolar lavage fluid: a tool for diagnosing aspergillosis in intensive care unit patients," American Journal of Respiratory and Critical Care Medicine, vol. 177, no. 1, pp. 27-34, 2008.

[27] J. Maertens, K. Theunissen, G. Verhoef et al., "Galactomannan and computed tomography-based preemptive antifungal therapy in neutropenic patients at high risk for invasive fungal infection: a prospective feasibility study," Clinical Infectious Diseases, vol. 41, no. 9, pp. 1242-1250, 2005. 
[28] N. Akamatsu, Y. Sugawara, J. Kaneko, S. Tamura, and M. Makuuchi, "Preemptive treatment of fungal infection based on plasma $(1->3) \beta$-D-glucan levels after liver transplantation," Infection, vol. 35, no. 5, pp. 346-351, 2007.

[29] Z. Odabasi, G. Mattiuzzi, E. Estey et al., " $\beta$-D-glucan as a diagnostic adjunct for invasive fungal infections: validation, cutoff development, and performance in patients with acute myelogenous leukemia and myelodysplastic syndrome," Clinical Infectious Diseases, vol. 39, no. 2, pp. 199-205, 2004.

[30] L. Ostrosky-Zeichner, B. D. Alexander, D. H. Kett et al., "Multicenter clinical evaluation of the $(1->3) \beta$-D-glucan assay as an aid to diagnosis of fungal infections in humans," Clinical Infectious Diseases, vol. 41, no. 5, pp. 654-659, 2005.

[31] C. Pazos, M. D. Moragues, G. Quindós, J. Pontón, and A. Del Palacio, "Diagnostic potential of $(1->3)-\beta-\mathrm{D}$ glucan and anti-Candida albicans germ tube antibodies for the diagnosis and therapeutic monitoring of invasive candidiasis in neutropenic adult patients," Revista Iberoamericana de Micologia, vol. 23, no. 4, pp. 209-215, 2006.

[32] C. Pazos, J. Pontón, and A. Del Palacio, "Contribution of $(1->3)-\beta$-D-glucan chromogenic assay to diagnosis and therapeutic monitoring of invasive aspergillosis in neutropenic adult patients: a comparison with serial screening for circulating galactomannan," Journal of Clinical Microbiology, vol. 43, no. 1, pp. 299-305, 2005.

[33] J. W. Pickering, H. W. Sant, C. A. P. Bowles, W. L. Roberts, and G. L. Woods, "Evaluation of a $(1->3)-\beta$-D-glucan assay for diagnosis of invasive fungal infections," Journal of Clinical Microbiology, vol. 43, no. 12, pp. 5957-5962, 2005.

[34] G. Quindos, M. D. Moragues, and J. Ponton, "Is there a role for antibody testing in the diagnosis of invasive candidiasis?" Revista Iberoamericana de Micología, vol. 21, pp. 10-14, 2004.

[35] M. D. Moragues, N. Ortiz, J. R. Iruretagoyena et al., "Evaluation of a new commercial test (Candida albicans IFA IgG) for the serodiagnosis of invasive candidiasis," Enfermedades Infecciosas y Microbiologia Clinica, vol. 22, no. 2, pp. 83-88, 2004.

[36] A. Y. Peleg and M. L. Woods, "Continuous and 4 h infusion of amphotericin B: a comparative study involving high-risk haematology patients," Journal of Antimicrobial Chemother$a p y$, vol. 54, no. 4, pp. 803-808, 2004.

[37] M. I. Morris and M. Villmann, "Echinocandins in the management of invasive fungal infections, part 1," American Journal of Health-System Pharmacy, vol. 63, no. 18, pp. 16931703, 2006.

[38] S. R. Ahmad, S. J. Singer, and B. G. Leissa, "Congestive heart failure associated with itraconazole," The Lancet, vol. 357, no. 9270, pp. 1766-1767, 2001.

[39] M. S. Saag, R. J. Graybill, R. A. Larsen et al., "Practice guidelines for the management of cryptococcal disease," Clinical Infectious Diseases, vol. 30, no. 4, pp. 710-718, 2000.

[40] D. Tassel and M. A. Madoff, "Treatment of Candida sepsis and Cryptococcus meningitis with 5-fluorocytosine. A new antifungal agent," Journal of the American Medical Association, vol. 206, no. 4, pp. 830-832, 1968.

[41] A. Polak and H. J. Scholer, "Mode of action of 5 fluorocytosine and mechanisms of resistance," Chemotherapy, vol. 21, no. 3-4, pp. 113-130, 1975.

[42] M. S. Bartlett, W. L. Current, M. P. Goheen et al., "Semisynthetic echinocandins affect cell wall deposition of Pneumocystis carinii in vitro and in vivo," Antimicrobial Agents and Chemotherapy, vol. 40, no. 8, pp. 1811-1816, 1996.

[43] M. A. Powles, P. Liberator, J. Anderson et al., "Efficacy of MK991 (L-743,872), a semisynthetic pneumocandin, in murine models of Pneumocystis carinii," Antimicrobial Agents and Chemotherapy, vol. 42, no. 8, pp. 1985-1989, 1998.

[44] M. B. Kurtz, G. Abruzzo, A. Flattery et al., "Characterization of echinocandin-resistant mutants of Candida albicans: genetic, biochemical, and virulence studies," Infection and Immunity, vol. 64, no. 8, pp. 3244-3251, 1996.

[45] M. A. Pfaller, L. Boyken, R. J. Hollis, S. A. Messer, S. Tendolkar, and D. J. Diekema, "In vitro susceptibilities of Candida spp. to caspofungin: four years of global surveillance," Journal of Clinical Microbiology, vol. 44, no. 3, pp. 760-763, 2006.

[46] D. Cappelletty and K. Eiselstein-McKitrick, "The echinocandins," Pharmacotherapy, vol. 27, no. 3, pp. 369-388, 2007.

[47] A. C. Pasqualotte and D. W. Denning, "New and emerging treatments for fungal infectionso," Journal of Antimicrobial Chemotherapy, vol. 61, supplement, pp. 119-130, 2008.

[48] G. Eschenauer, D. D. DePestel, and P. L. Carver, "Comparison of echninocandin antifungals," Therapeutics and Clinical Risk Management, vol. 3, no. 1, pp. 71-97, 2007.

[49] C. M. Douglas, J. A. D’Ippolito, G. J. Shei et al., "Identification of the FKS1 gene of Candida albicans as the essential target of 1,3- $\beta$-D-glucan synthase inhibitors," Antimicrobial Agents and Chemotherapy, vol. 41, no. 11, pp. 2471-2479, 1997.

[50] E. G. Arathoon, E. Gotuzzo, L. M. Noriega, R. S. Berman, M. J. DiNubile, and C. A. Sable, "Randomized, doubleblind, multicenter study of caspofungin versus amphotericin B for treatment of oropharyngeal and esophageal candidiases," Antimicrobial Agents and Chemotherapy, vol. 46, no. 2, pp. 451-457, 2002.

[51] S. Kishino, K. Ohno, T. Shimamura, H. Furukawa, and S. Todo, "Optimal prophylactic dosage and disposition of micafungin in living donor liver recipients," Clinical Transplantation, vol. 18, no. 6, pp. 676-680, 2004.

[52] A. Solé and M. Salavert, "Voriconazole for the therapy of mycoses in recipients of solid organ transplants," Revista Iberoamericana de Micologia, vol. 24, no. 3, pp. 217-222, 2007.

[53] J. R. Wingard and H. Leather, "A new era of antifungal therapy," Biology of Blood and Marrow Transplantation, vol. 10, no. 2, pp. 73-90, 2004.

[54] B. J. Spellberg, S. G. Filler, and J. E. Edwards, "Current treatment strategies for disseminated candidiasis," Clinical Infectious Diseases, vol. 42, no. 2, pp. 244-251, 2006.

[55] B. D. Brielmaier, E. Casabar, C. M. Kurtzeborn, P. S. McKinnon, and D. J. Ritchie, "Early clinical experience with anidulafungin at a large tertiary care medical center," Pharmacotherapy, vol. 28, no. 1, pp. 64-73, 2008.

[56] N. Singh, A. P. Limaye, G. Forrest et al., "Combination of voriconazole and caspofungin as primary therapy for invasive aspergillosis in solid organ transplant recipients: a prospective, multicenter, observational study," Transplantation, vol. 81, no. 3, pp. 320-326, 2006.

[57] J. W. Baddley and P. G. Pappas, "Antifungal combination therapy: clinical potential," Drugs, vol. 65, no. 11, pp. 14611480, 2005.

[58] H. M. Blumberg, W. R. Jarvis, J. M. Soucie et al., "Risk factors for candidal bloodstream infections in surgical intensive care unit patients: the NEMIS prospective multicenter study," Clinical Infectious Diseases, vol. 33, no. 2, pp. 177-186, 2001.

[59] P. A. Lipsett, "Surgical critical care: fungal infections in surgical patients," Critical Care Medicine, vol. 34, no. 9, supplement, pp. S215-S224, 2006.

[60] W. E. Trick, S. K. Fridkin, J. R. Edwards, R. A. Hajjeh, and R. P. Gaynes, "Secular trend of hospital-acquired Candidemia among intensive care unit patients in the United States 
during 1989-1999," Clinical Infectious Diseases, vol. 35, no. 5, pp. 627-630, 2002.

[61] R. Ben-Abraham, N. Keller, N. Teodorovitch et al., "Predictors of adverse outcome from candidal infection in a tertiary care hospital," Journal of Infection, vol. 49, no. 4, pp. 317-323, 2004.

[62] C. M. Beck-Sague and W. R. Jarvis, "Secular trends in the epidemiology of nosocomial fungal infections in the United States, 1980-1990," Journal of Infectious Diseases, vol. 167, no. 5, pp. 1247-1251, 1993.

[63] Centers for Disease Control, "National nosocomial infections surveillance (NNIS) system report, DATA summary from January 1982-June 2003," American Journal of Infection Control, vol. 31, pp. 481-498, 2003.

[64] H. Wisplinghoff, T. Bischoff, S. M. Tallent, H. Seifert, R. P. Wenzel, and M. B. Edmond, "Nosocomial bloodstream infections in US hospitals: analysis of 24,179 cases from a prospective nationwide surveillance study," Clinical Infectious Diseases, vol. 39, no. 3, pp. 309-317, 2004.

[65] R. Zaragoza and J. Pemán, "Invasive fungal infections in critically ill patients: different therapeutic options and a uniform strategy," Revista Iberoamericana de Micologia, vol. 23, no. 2, pp. 59-63, 2006.

[66] J. H. Rex, J. E. Bennett, A. M. Sugar et al., "A randomized trial comparing fluconazole with amphotericin B for the treatment of candidemia in patients without neutropenia," The New England Journal of Medicine, vol. 331, no. 20, pp. 1325-1330, 1994.

[67] J. Mora-Duarte, R. Betts, C. Rotstein et al., "Comparison of caspofungin and amphotericin B for invasive candidiasis," The New England Journal of Medicine, vol. 347, no. 25, pp. 2020 2029, 2002.

[68] C. Lumbreras, V. Cuervas-Mons, P. Jara et al., "Randomized trial of fluconazole versus nystatin for the prophylaxis of Candida infection following liver transplantation," Journal of Infectious Diseases, vol. 174, no. 3, pp. 583-588, 1996.

[69] P. Phillips, S. Shafran, G. Garber et al., "Multicenter randomized trial of fluconazole versus amphotericin B for treatment of candidemia in non-neutropenic patients," European Journal of Clinical Microbiology and Infectious Diseases, vol. 16, no. 5, pp. 337-345, 1997.

[70] A. M. Rentz, M. T. Halpern, and R. Bowden, "The impact of candidemia on length of hospital stay, outcome, and overall cost of illness," Clinical Infectious Diseases, vol. 27, no. 4, pp. 781-788, 1999.

[71] J. F. Whiting, J. Martin, E. Zavala, and D. Hanto, "The influence of clinical variables on hospital costs after orthotopic liver transplantation," Surgery, vol. 125, no. 2, pp. 217-222, 1999.

[72] J. J. Gagne, R. E. Breithart, V. Maio et al., "Costs associatd with candidemia in a hospital setting," $P$ and $T$, vol. 31, no. 10, pp. 586-619, 2006.

[73] F. P. Silveira and S. Husain, "Fungal infections in solid organ transplantation,” Medical Mycology, vol. 45, no. 4, pp. 305320, 2007.

[74] M. Cruciani, C. Mengoli, M. Malena, O. Bosco, G. Serpelloni, and P. Grossi, "Antifungal prophylaxis in liver transplant patients: a systematic review and meta-analysis," Liver Transplantation, vol. 12, no. 5, pp. 850-858, 2006.

[75] N. Singh, "Antifungal prophylaxis in solid-organ transplant recipients: considerations for clinical trial design," Clinical Infectious Diseases, vol. 39, supplement 4, pp. S200-S206, 2004.

[76] E. G. Playford, A. C. Webster, T. C. Sorell, and J. C. Craig, "Antifungal agents for preventing fungal infections in solid organ transplant recipients," Cochrane Database of Systematic Reviews, no. 3, Article ID CD004291, 2004.

[77] S. Husain, J. Tollemar, E. A. Dominguez et al., "Changes in the spectrum and risk factors for invasive candidiasis in liver transplant recipients: prospective, multicenter, case-controlled study," Transplantation, vol. 75, no. 12, pp. 2023-2029, 2003.

[78] N. Singh, "Invasive aspergillosis in organ transplant recipients: new issues in epidemiologic characteristics, diagnosis, and management," Medical Mycology, vol. 43, no. 1, pp. S267S270, 2005.

[79] M. Morrell, V. J. Fraser, and M. H. Kollef, "Delaying the empiric treatment of Candida bloodstream infection until positive blood culture results are obtained: a potential risk factor for hospital mortality," Antimicrobial Agents and Chemotherapy, vol. 49, no. 9, pp. 3640-3645, 2005.

[80] P. Eggimann, P. Francioli, J. Bille et al., "Fluconazole prophylaxis prevents intra-abdominal candidiasis in high-risk surgical patients," Critical Care Medicine, vol. 27, no. 6, pp. 1066-1072, 1999.

[81] J. Fortún, P. Martín-Dávila, S. Moreno et al., "Prevention of invasive fungal infections in liver transplant recipients: the role of prophylaxis with lipid formulations of amphotericin B in high-risk patients," Journal of Antimicrobial Chemotherapy, vol. 52, no. 5, pp. 813-819, 2003.

[82] N. Singh, A. P. Limaye, G. Forrest et al., "Combination of voriconazole and caspofungin as primary therapy for invasive aspergillosis in solid organ transplant recipients: a prospective, multicenter, observational study," Transplantation, vol. 81, no. 3, pp. 320-326, 2006.

[83] N. Singh, T. L. Pruett, S. Houston et al., "Invasive aspergillosis in the recipients of liver retransplantation," Liver Transplantation, vol. 12, no. 8, pp. 1205-1209, 2006.

[84] T. J. Walsh, P. Pappas, D. J. Winston et al., "Voriconazole compared with liposomal amphotericin B for empirical antifungal therapy in patients with neutropenia and persistent fever," The New England Journal of Medicine, vol. 346, no. 4, pp. 225-234, 2002.

[85] J. Fortun, M. Montejo, P. Martin-Davila et al., "Prospective, multicentre study of caspofungin for prophylaxis in highrisk liver transplantation," in Proceedings of the 17th European Congress of Clinical Microbiology and Infectious Diseases (ICC '07), pp. 1733-1763, Munich, Germany, March 2007.

[86] M. D. Sharpe, C. Ghent, D. Grant, G. L. A. Horbay, J. McDougal, and W. D. Colby, "Efficacy and safety of itraconazole prophylaxis for fungal infections after orthotopic liver transplantation: a prospective, randomized, double-blind study," Transplantation, vol. 76, no. 6, pp. 977-983, 2003.

[87] J. Tollemar, K. Hockerstedt, B. G. Ericzon, H. Jalanko, and O. Ringden, "Liposomal amphotericin B prevents invasive fungal infections in liver transplant recipients. A randomized, placebo-controlled study," Transplantation, vol. 59, no. 1, pp. 45-50, 1995.

[88] N. Singh, D. L. Paterson, T. Gayowski, M. M. Wagener, and I. R. Marino, "Preemptive prophylaxis with a lipid preparation of amphotericin B for invasive fungal infections in liver transplant recipients requiring renal replacement therapy," Transplantation, vol. 71, no. 7, pp. 910-913, 2001. 


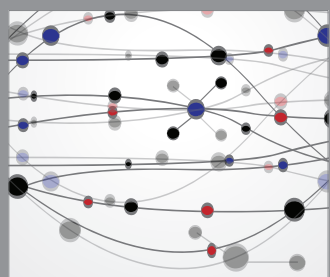

The Scientific World Journal
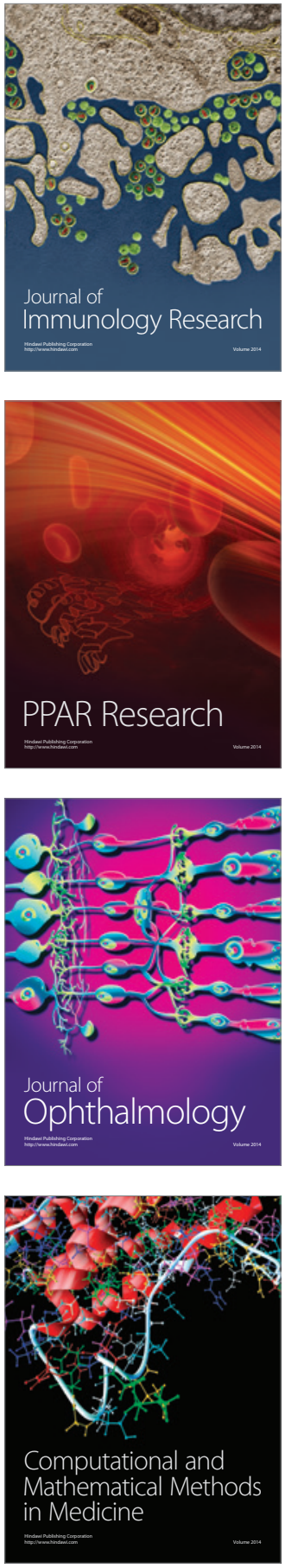

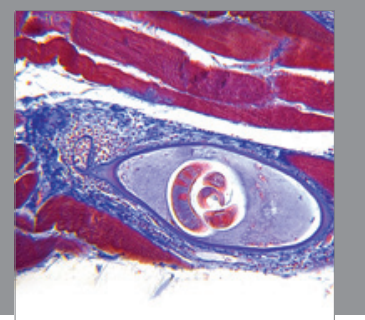

Gastroenterology

Research and Practice
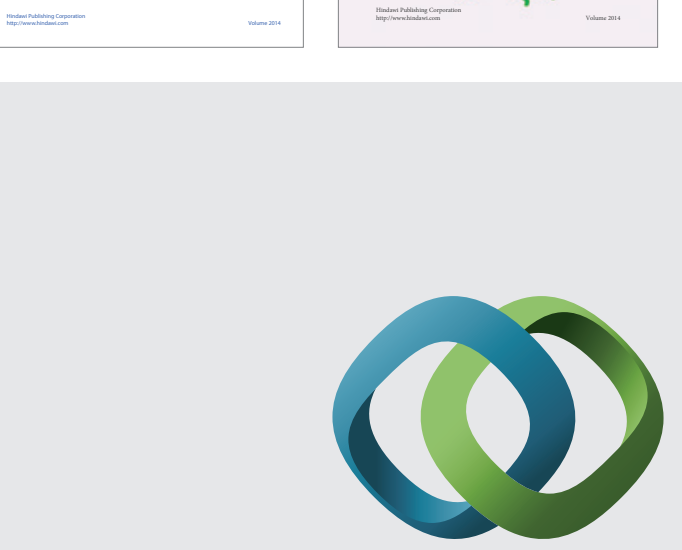

\section{Hindawi}

Submit your manuscripts at

http://www.hindawi.com
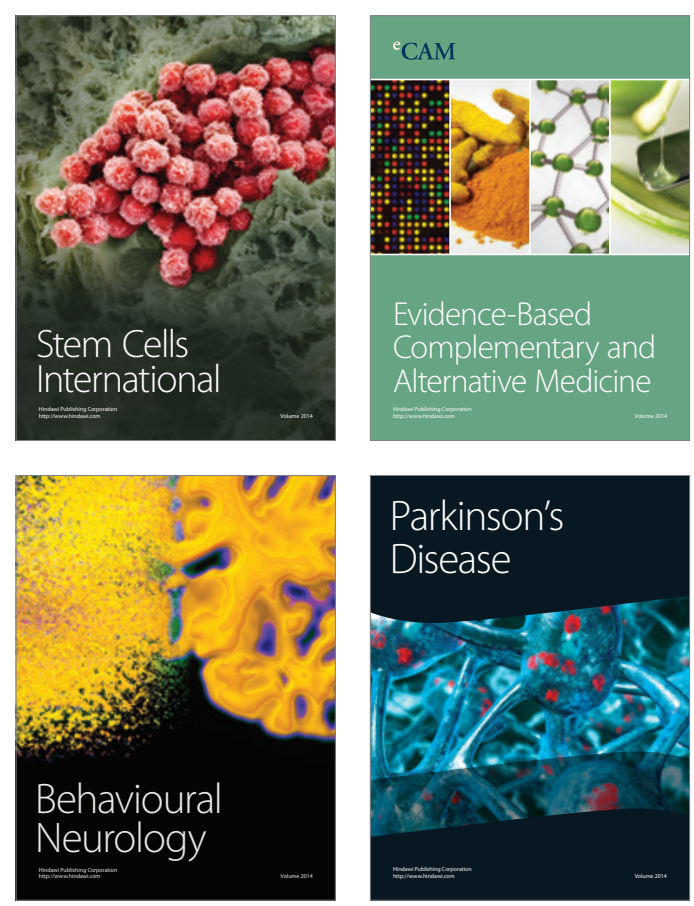

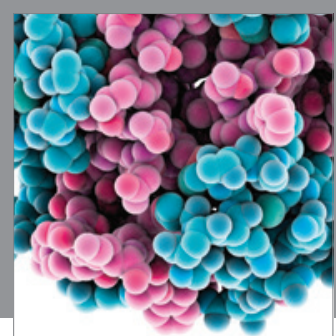

Journal of
Diabetes Research

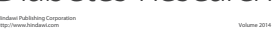

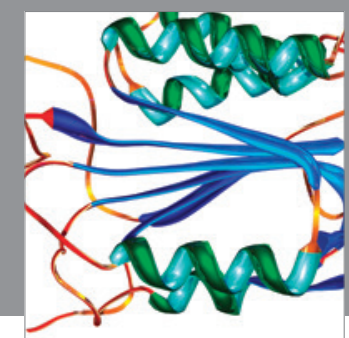

Disease Markers
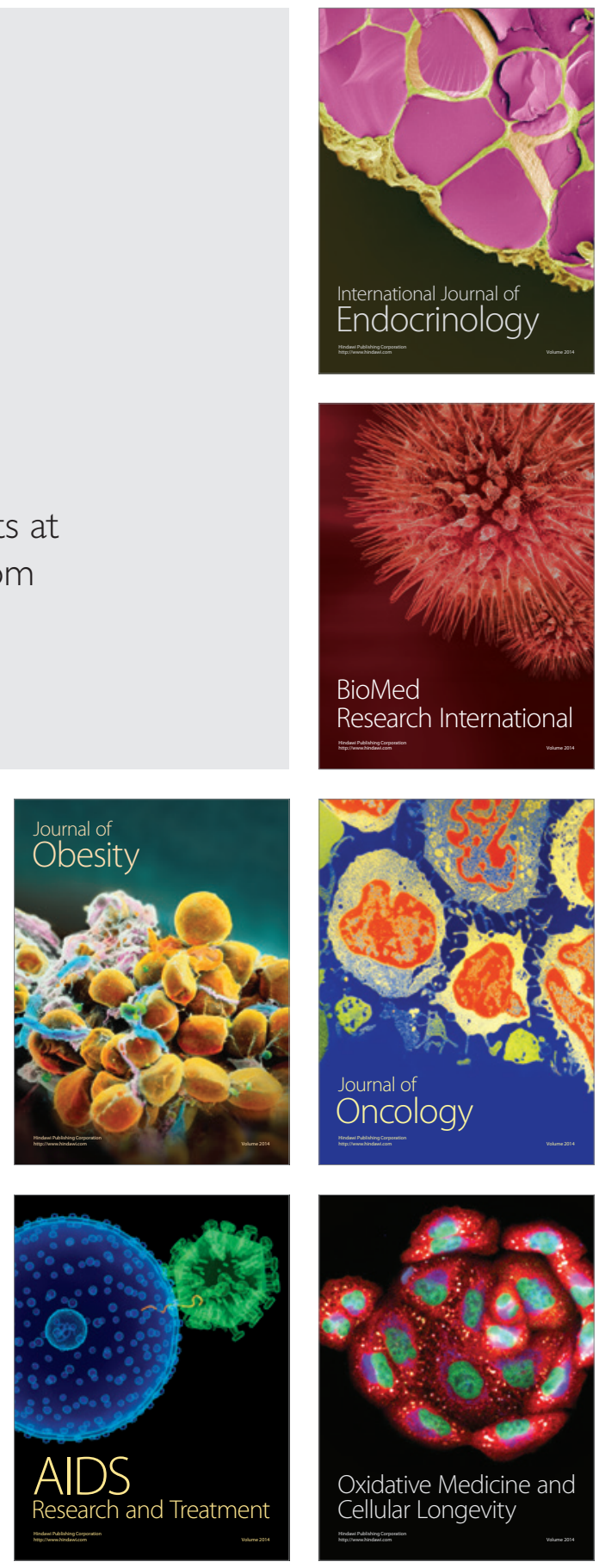